\title{
The Vitamin E Analog Gamma-Tocotrienol (GT3) Suppresses Radiation-Induced Cytogenetic Damage
}

\author{
Rupak Pathak' - Abdel Bachri ${ }^{2}$ - Sanchita P. Ghosh ${ }^{3}$ • Igor Koturbash ${ }^{4}$ - Marjan Boerma' . \\ Regina K. Binz ${ }^{5}$ • Jeffrey R. Sawyer ${ }^{5}$. Martin Hauer-Jensen ${ }^{1,6}$
}

Received: 23 February 2016 / Accepted: 13 May 2016 / Published online: 23 May 2016

(C) The Author(s) 2016. This article is published with open access at SpringerLink.com

\begin{abstract}
Purpose Ionizing radiation (IR) generates reactive oxygen species (ROS), which cause DNA double-strand breaks (DSBs) that are responsible for cytogenetic alterations. Because antioxidants are potent ROS scavengers, we determined whether the vitamin $\mathrm{E}$ isoform $\gamma$-tocotrienol (GT3), a radio-protective multifunctional dietary antioxidant, can suppress IR-induced cytogenetic damage.
\end{abstract}

Methods We measured DSB formation in irradiated primary human umbilical vein endothelial cells (HUVECs) by quantifying the formation of $\gamma$-H2AX foci. Chromosomal aberrations (CAs) were analyzed in irradiated HUVECs and in the bone marrow cells of irradiated mice by conventional and fluorescence-based chromosome painting techniques. Gene expression was measured in HUVEGs with quantitative reverse transcriptase polymerase chain reaction (qRT-PCR).

Results GT3 pretreatment reduced DSB formation in HUVECS, and also decreased CAs in HUVECs and mouse bone marrow cells after irradiation. Moreover, GT3 increased

Rupak Pathak

rpathak@uams.edu

Division of Radiation Health, Department of Pharmaceutical

Sciences, College of Pharmacy, University of Arkansas for Medical

Sciences, Biomed I, Suite 238, 430 I West Markham, Slot 522-3, Little Rock, Arkansas 72205, USA

2 Department of Engineering and Engineering Physics, Southern Arkansas University, Magnolia, Arkansas, USA

3 Armed Forces Radiobiology Research Institute, USUHS, Bethesda, Maryland, USA

4 Department of Environmental and Occupational Health, University of Arkansas for Medical Sciences, Little Rock, Arkansas, USA

5 Department of Pathology, University of Arkansas for Medical Sciences, Little Rock, Arkansas, USA

6 Central Arkansas Veterans Healthcare System, Little Rock, Arkansas, USA expression of the DNA-repair gene RAD50 and attenuated radiation-induced $R A D 50$ suppression.

Conclusions GT3 attenuates radiation-induced cytogenetic damage, possibly by affecting RAD50 expression. GT3 should be explored as a therapeutic to reduce the risk of developing genetic diseases after radiation exposure.

KEY WORDS chromosomal aberrations . DNA repair . endothelial cells $\cdot$ gamma-tocotrienol $\cdot$ ionizing radiation

$\begin{array}{ll}\text { ABBREVIATIONS } \\ \text { APC } & \text { Activated protein } \mathrm{C} \\ \text { CAs } & \text { Chromosomal aberrations } \\ \text { DMSO } & \text { Dimethyl sulfoxide } \\ \text { DSBs } & \text { DNA double strand breaks } \\ \text { EPCR } & \text { Endothelial protein C receptor } \\ \text { G-CSF } & \text { Granulocyte colony stimulating factor } \\ \text { GT3 } & \text {-tocotrienol } \\ \text { Gy } & \text { Gray unit } \\ \text { HUVECS } & \text { Human umbilical vein endothelial cells } \\ \text { IR } & \text { Ionizing radiation } \\ \text { mFISH } & \text { Multiple fluorescence in situ hybridization } \\ \text { qRT- } & \text { Quantitative reverse transcriptase polymerase } \\ \text { PCR } & \text { chain reaction } \\ \text { Rad50 } & \text { RAD50 homolog, double strand break repair } \\ & \text { protein } \\ \text { ROS } & \text { Reactive oxygen species } \\ \text { TM } & \text { Thrombomodulin }\end{array}$

\section{INTRODUCTION}

Ionizing radiation (IR) compromises the redox state of cells and generates reactive oxygen species (ROS) in excess. ROS are highly reactive and damage DNA, as well as various cellular components. Mammalian cells exposed to 1 Gy of IR 
accumulate approximately 1000 single-strand breaks, 40 double-strand breaks (DSBs), and 3000 damaged DNA bases (1). DSBs are serious lesions that can cause numerous structural chromosomal aberrations (CAs) such as sister chromatid unions, chromatid- or chromosome-type breaks, and dicentric or ring chromosomes (2). Such CAs are particularly deleterious and are associated with the progression and development of several diseases, including cancer (3). To date, CAs have been found in all major tumor types and are also associated with mental illness, congenital heart disease, and respiratory problems (4-6). This suggests that CAs are not only a hallmark of cancer but also a cytogenetic signature of various pathophysiological conditions. While CAs can arise spontaneously, radiation is a major factor that induces CAs.

DNA-repair proteins such as RAD50 mitigate CAs by repairing DSBs. Curiously, radiation suppresses $R A D 50$ gene expression in mouse white blood cells for up to $48 \mathrm{~h}$ after irradiation (7). RAD50 is part of the MRN complex which consists of meiotic recombination 11 (MRE11), RAD50, and Nijmegen breakage syndrome 1 (NBS1) proteins. The primary function of the MRN complex is to recognize DSBs, bind the damaged DNA, and initiate repair by regulating the homologous recombination pathway and the alternate-nonhomologous end- joining cascade with support from other DNA-repair proteins (8).

The type and frequency of radiation-induced CAs vary with radiation dose, dose rate, and the quality of irradiation. CAs may be evident in metaphase chromosomes soon after irradiation, or they may appear several generations later. This delay is a sign of genomic instability and is a hallmark of cancer (9). Similarly, IR is a major risk factor for endothelial dysfunction (10), and genetically unstable endothelial cells can directly stimulate cancer metastases $(11,12)$. Thus, both cancer and endothelial dysfunction may benefit from therapies that reduce radiation-induced oxidative stress.

Antioxidants suppress DSBs and CAs in irradiated human lymphocytes $(13,14)$. The vitamin $\mathrm{E}$ isoform $\boldsymbol{\gamma}$-tocotrienol (GT3) is a natural dietary antioxidant and a potent radioprotector, with the largest dose reduction factor among all the natural products identified to date $(15,16)$. GT3 protects the endothelials cells that line the blood and lymphatic vessels of higher eukaryotes (17), regulates a number of signaling pathways that mitigate radiation damage (18), and also protects mice from a lethal dose of radiation (16). Although we do not fully understand how GT3 protects against radiation damage, studies by various groups, including our own, suggest that GT3 may regulate apoptotic signals, cytokine production, cholesterol biosynthesis, or progenitor cell mobilization (17,19-21). Moreover, gene-expression profiles suggest that GT3 affects a number of genes known to be important for the DNA damage response (18).

Here, we demonstrate that GT3 pretreatment decreases the frequency of radiation-induced DSBs and CAs both in vitro and in viwo. We also show that GT3 stabilizes RAD50 expression after irradiation. These findings suggest that GT3 is a potent radio-protector that can protect against radiationinduced cytogenetic damage.

\section{MATERIALS AND METHODS}

\section{Materials}

GT3 was obtained from Yasoo Health Inc. Johnson City, TN). The EGM-2 Bullet Kit and HEPES-buffered saline solution used for cell culture were obtained from Lonza (Walkersville, MD). All other reagents and media were obtained from Sigma (St. Louis, MO).

\section{Cell Culture and Animals}

Primary human umbilical vein endothelial cells (HUVECs) (American Type Culture Collection, Manassas, VA) were cultured in tissue culture vessels with EGM-2 Bullet Kit in 5\% $\mathrm{CO}_{2}$ incubator at $37^{\circ} \mathrm{C}$. The cells were passaged every 2 to 3 days with standard aseptic techniques, and experiments were performed using cells from passages 3 to 6 .

All animal studies were carried out in strict accordance with the Guide for the Care and Use of Laboratory Animals of the National Institutes of Health. The animal protocol was approved by the Institutional Animal Care and Use Committee of the University of Arkansas for Medical Sciences. Female C57BL/6J mice (The Jackson Laboratory, Bar Harbor, ME, stock no. 000664) were held in quarantine for 1 week after arrival. All animals were housed in conventional cages in a standard air conditioned animal facility at 20 $\pm 2^{\circ} \mathrm{C}$, with $10-15$ hourly cycles of fresh air, and a 12-12-h day-night light cycle. Animals had free access to water and chow (Envigo Teklad diet 7012, Madison, WI). All animals were humanely euthanized with $\mathrm{CO}_{2}$ in an appropriate chamber.

\section{Irradiation and Drug Treatment}

Mice were irradiated with a single, total-body radiation dose (3 Gy) in a Shepherd Mark I model $25{ }^{137}$ Cs irradiator (J. L. Shepherd \& Associates, San Fernando, CA). The average dose rate was $0.98 \mathrm{~Gy} / \mathrm{min}$ and was corrected for decay. The animals were placed in a well-ventilated rotating chamber composed of T-6061 aluminum with a gold-anodized coating. The chamber was divided into eight equal "pie slice" compartments with a well-ventilated Plexiglas lid (J.L. Shepherd \& Associates). Animals were injected subcutaneously into the loose skin over the neck with a single dose of GT3 or vehicle (5\% Tween-80 in saline) $24 \mathrm{~h}$ before irradiation. All radiation experiments were performed in the morning to 
minimize diurnal effects. HUVEGs were irradiated in T25 tissue-culture flasks (Corning, NY) or chambered slides (Nunc Lab-Tek, St. Louis, MO). HUVECs were treated with 0-5 $\mu \mathrm{M}$ of GT3 or vehicle (DMSO) prior to irradiation. Radiation doses used for the various studies were carefully selected based on experimental endpoints and knowledge regarding cellular radio-sensitivity.

\section{Y-H2AX Detection}

HUVECs were grown in 4-well chambered slides overnight and treated with GT3 or vehicle (DMSO) for $1 \mathrm{~h}$ or $24 \mathrm{~h}$ before irradiation. Cells were washed with PBS and fixed with $4 \%$ paraformaldehyde $1 \mathrm{~h}$ after irradiation. The fixed cells were washed, permeabilized with $0.3 \%$ Triton-X for $15 \mathrm{~min}$ at room temperature, quenched with $1 \%$ glycine, and blocked with $4 \%$ BSA in $1 \mathrm{X}$ TBST overnight at $4^{\circ} \mathrm{C}$. The cells were incubated with primary antibody (1:600 dilution; monoclonal Anti-phospho-Histone H2AX (Ser139), clone JBW301; Millipore, Temecula, CA) for $3 \mathrm{~h}$ at room temperature. After washing 3 times with PBS, secondary antibody (Alexa Fluor 594 F (ab') 2 fragment of goat anti-mouse IgG; Invitrogen, Grand Island, NY) was added, and the cells were incubated for $1 \mathrm{~h}$ at room temperature in the dark. Finally, the cells were washed with PBS and stained with Hoechst solution to visualize nuclei. $\gamma$-H2AX foci were detected with a Zeiss AxioPlan microscope. $\gamma$-H2AX foci were not counted in apoptotic cells. The apoptotic cells, particularly cells in late apoptotic stages, were identified by their highly compromised nuclear membrane.

\section{Preparation of Metaphase Spreads}

For in vitro experiments, HUVECs were treated with $5 \mu \mathrm{l} / \mathrm{ml}$ colcemid (Invitrogen, Grand Island, NY) $24 \mathrm{~h}$ before cell harvest. HUVECs were collected by trypsinization and washed 2 times with PBS. For in vivo experiments, mice were given $100 \mu \mathrm{l}$ of $0.05 \%$ colchicine intraperitoneally $2 \mathrm{~h}$ before bone marrow harvest. Bone marrow cells were collected from the tibias and femurs of both hind legs by flushing with ice cold PBS containing 2\% FBS. The cell suspension was layered onto equal volume $(3 \mathrm{ml}$ ) of Histopaque-1083 (SigmaAldrich, St. Louis, MO) in a $15-\mathrm{ml}$ tube. The tubes were centrifuged at $400 \mathrm{~g}$ for $30 \mathrm{~min}$ at room temperature. The buffy coat, containing bone marrow mononuclear cells, was collected and washed with PBS. HUVECs and mouse bone marrow mononuclear cells were then treated with hypotonic solution $(0.56 \% \mathrm{KCl}$ solution) for $15 \mathrm{~min}$ and fixed in methanol-acetic acid (3:1). Fixed cells were applied to precleaned, wet glass slides and air-dried overnight at room temperature.

\section{Chromosome Staining Techniques}

Two techniques were used to examine CAs in metaphase spreads. Giemsa staining: Metaphase spreads were prepared as described above and air dried at room temperature overnight. Slides were immersed in Giemsa staining solution (Fisher Scientific) for $20 \mathrm{~min}$, rinsed in distilled water to remove excess stain, and air-dried for $24 \mathrm{~h}$ before scoring at 100x magnification under bright field on a Zeiss microscope. Multiple fluorescence in situ hybridization (mFISH) painting: Whole-chromosome DNA probes (Applied Spectral Imaging, Carlsbad, CA) were used to label human and mouse chromosomes 1, 2, and 3, according to the manufacturer's instructions. Metaphase spreads were prepared $24 \mathrm{~h}$ before mFISH painting. The slides were treated with 2X SSC buffer at room temperature for $2 \mathrm{~min}$, then dehydrated in a series of ethanol solutions $(70 \%, 80 \%$, and $100 \%)$ for $2 \mathrm{~min}$ each. Chromosomes were denatured by placing the slides in prewarmed $\left(72^{\circ} \mathrm{C}\right)$ denaturation solution $(70 \%$ formamide in 2X SSC) for 60-80 s, then immediately passed through a series of cold ethanol solutions $(70 \%, 80 \%$, and $100 \%)$ and air-dried. mFISH probe $(10 \mu \mathrm{l})$ was denatured at $80^{\circ} \mathrm{C}$ for $7 \mathrm{~min}$ and applied to the slides. The slides were covered with glass cover slips, sealed with rubber cement, and incubated overnight at $37^{\circ} \mathrm{C}$ in a humidified $\mathrm{CO}_{2}$ incubator. The coverslips were removed, and the slides were washed with $0.4 \mathrm{X}$ SSC at $74^{\circ} \mathrm{C}$ for $5 \mathrm{~min}$ and placed in washing solution-II (4X SSC with $0.1 \%$ Tween-20) for 2 min. Finally, the slides were counter-stained with $10 \mu \mathrm{l}$ of DAPI containing anti-fade (Vector Laboratories, Burlingame, CA) and sealed with a coverslip.

\section{qRT-PCR}

HUVEGs were washed twice with cold calcium- and magnesium-free PBS. Total RNA was extracted with the RNeasy Plus Mini Kit (Qiagen, Valencia, CA), and each sample was treated with TURBO DNase (Ambion, Grand Island, NY). RNA was quantified with an Agilent 2100 Bioanalyzer (Agilent Technologies, Santa Clara, CA). Samples with an RNA integrity number (RIN) of 10 were used to produce cDNA. Although in a typical in vitro experiment RIN value varies between 7.5 and 10 , in the current study we used samples with RIN value 10 to ensure reproducibility and accuracy of the gene expression study. cDNA was generated from $2 \mu \mathrm{g}$ of RNA using the high-capacity cDNA Reverse Transcription Kit (Applied Biosystems, Carlsbad, CA). qRT-PGR was performed with the ABI Prism 7000 Sequence Detection System (Applied Biosystems). Standard real-time PGR $\left(50^{\circ} \mathrm{C}\right.$ for $2 \mathrm{~min} ; 95^{\circ} \mathrm{C}$ for $10 \mathrm{~min} ; 50$ cycles of $95^{\circ} \mathrm{C}$ for $15 \mathrm{~s}, 60^{\circ} \mathrm{C}$ for $60 \mathrm{~s})$ was performed with TaqMan 2X Universal PCR Master Mix (Applied Biosystems). Relative mRNA expression was 
calculated with the comparative $C_{\mathrm{T}}$ method $\left(2^{-\Delta \Delta C \mathrm{~T}}\right)$ and normalized to $18 \mathrm{~S}$ rRNA for each sample.

\section{Statistical Analysis}

Statistical analyses were performed with GraphPad software (La Jolla, CA). For experiments with only one parameter under consideration, $p$ values were determined by an unpaired Student's $t$ test. The standard error for CAs was calculated by $\sqrt{ } a / A$, where $a$ was the number of aberration under consideration and $A$ was the total number of cells analyzed (22). Z tests were used to test differences in the frequency of CAs before and after exposure to IR, as described elsewhere (23). Results were considered statistically significant when $p<0.05$.

\section{RESULTS}

\section{GT3 Suppresses Radiation-Induced DSB Formation in Primary Human Endothelial Cells}

Because GT3 has strong antioxidant properties and protects endothelial cells from radiation damage $(15,17)$, we proposed that GT3 pretreatment would suppress radiation-induced DSBs in HUVECs. To determine whether GT3 was able to suppress DSBs in HUVECs, we assayed the formation of $\gamma$ H2AX foci as an indicator of DSBs after irradiation. Previous gene expression profiling study from our group show that GT3 treatment for $24 \mathrm{~h}$ substantially alters genetic pathways known to be of critically important in the regulation of cellular responses of radiation exposure, including the responses to DNA damage stimuli in HUVECs (18). However, a recent study demonstrate GT3 treatment for 1 h considerably sup- presses AKT phosphorylation, another critical marker of DSBs formation, in HUVEGs (24). Therefore, we decided to treat HUVEGs with GT3 either for $1 \mathrm{~h}$ or $24 \mathrm{~h}$ to assess its ability to modify radiation-induced $\gamma \mathrm{H} 2 \mathrm{AX}$ foci formation. HUVECs were treated with either $5 \mu \mathrm{M}$ GT3 or vehicle (DMSO) $24 \mathrm{~h}$ before irradiation with 0.2 Gy of $\gamma$-rays. $\gamma$-H2AX foci were quantified by microscopy $1 \mathrm{~h}$ after irradiation (a low dose of radiation was used to minimize counting error). $\gamma$-H2AX foci were almost undetectable in non-irradiated cells treated with vehicle or GT3 (Fig. 1a I, II, b). Irradiation induced $\gamma$-H2AX foci in both the vehicle- $(3.8 \pm 0.07)$ and GT3-treated groups $(2.7 \pm 0.23)$ but the GT3-treated cells contained significantly $(p=0.01)$ fewer $\gamma$-H2AX foci (Fig. 1a III, VI, b). Further, to determine the ability of GT3 in suppressing residual DSBs that are persisted several hours after irradiation, we treated HUVECs with $5 \mu \mathrm{M}$ of GT3 for $1 \mathrm{~h}$, then exposed to two different radiation doses $3 \mathrm{~Gy}$ and $5 \mathrm{~Gy}$, and further incubated for $29 \mathrm{~h}$ before immunofluorescence staining for $\gamma$ H2AX foci. We observed GT3 also effectively suppressed frequency of persistent DSB formation in primary human endothelial cells after 3 Gy $(3.4 \pm 0.19$ in vehicle treated group vs $2.0 \pm 0.46$ in GT3 treated group) and 5 Gy $(4.4 \pm 0.31$ in vehicle treated group vs $3.2 \pm 0.23$ in GT3 treated group) irradiation (Fig. 1c).

\section{GT3 Decreases Chromosomal Aberrations in Irradiated Primary Human Endothelial Cells}

Next, we asked whether GT3 pretreatment could decrease CAs in irradiated endothelial cells. HUVECs were irradiated with 5 Gy, and CAs were visualized with Giemsa staining and

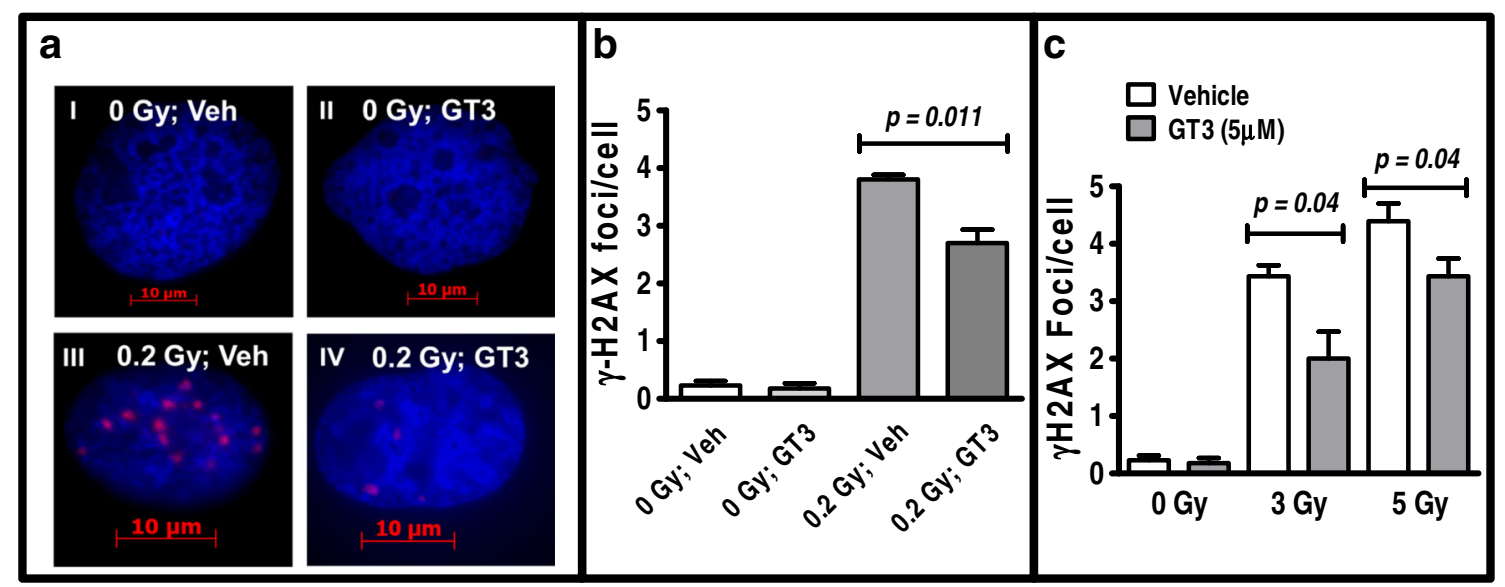

Fig. I GT3 decreases the number of radiation-induced $\mathrm{Y}$-H2AX foci (red) in HUVEC nuclei (DAPI stain, blue). (a) HUVECs were treated with (I) vehicle (Veh, DMSO) for $24 \mathrm{~h}$ or (II) $5 \mu$ M GT3 for $24 \mathrm{~h}$ without irradiation, or (III) pretreated with vehicle or (IV) $5 \mu$ M GT3 $24 \mathrm{~h}$ before 0.2 Gy irradiation. Images were taken I h after irradiation. (b) Data from (a) are expressed as $\mathrm{Y}-\mathrm{H} 2 \mathrm{AX}$ foci per cell for each treatment. (c) To determine the efficacy of GT3 in suppressing persistent DSBs, HUVECs were treated with GT3 or vehicle for I h, exposed to 0, 3 and $5 \mathrm{~Gy}$ of radiation and further incubated for $29 \mathrm{~h}$ before $\mathrm{YH} 2 \mathrm{AX}$ immunofluorescence staining. At least 200 nuclei were counted per treatment group. The data are presented as the mean \pm SEM of 3 to 6 independent assays and $p$ values were determined by an unpaired Student's $t$ test. 
mFISH analysis with probes specific for human chromosomes 1, 2, and 3. CAs were scored as chromatid-type breaks, sister chromatid unions, chromatid-type exchanges, dicentric and ring chromosomes, double minutes, and chromosome-type breaks. The percentage of radiation-induced CAs was lower in HUVECs pretreated with GT3 $(115.6 \pm 13.4)$ than in the vehicle-treated group (176.3 \pm 15.2$)$, as detected by Giemsa staining (Table I). Likewise, the number of radiationinduced CAs in chromosomes 1, 2, and, 3 was lower in HUVEGs pretreated with GT3 $(90.5 \pm 11.1)$ than in the vehicle-treated group (128.4 \pm 10.5$)$ (Table II). Thus, GT3 effectively decreased DSBs and CAs in HUVECs.

\section{GT3 Decreases Chromosomal Aberrations in Irradiated Mice}

Considering that GT3 effectively decreased CAs in vitro, we predicted that GT3 would decrease CAs in mice after irradiation. Mice were administered GT3 $(100 \mu \mathrm{l}$ at dose of $200 \mathrm{mg} / \mathrm{kg}$ ) subcutaneously $24 \mathrm{~h}$ before $3 \mathrm{~Gy}$ of total-body irradiation, and bone marrow mononuclear cells were collected $24 \mathrm{~h}$ or 30 days after irradiation. We used a relatively lower dose (3 Gy) for the in vivo study than for the in vitro chromosomal aberration assay (5 Gy) because lymphocytes are more radiosensitive than HUVECs. Giemsa staining detected CAs in mouse bone marrow cells $24 \mathrm{~h}$ after irradiation (Fig. 2b, arrows), compared to the non-irradiated control (Fig. 2a). However, GT3 suppressed CAs in the irradiated bone marrow cells both $24 \mathrm{~h}(p=0.0001)$ and 30 days $(p=0.007)$ after irradiation (Fig. 2c). GT3 treatment also significantly $(p<0.01)$ decreased radiation-induced CAs involving mouse chromosomes 1, 2, and $324 \mathrm{~h}$ after irradiation (Fig. 3). Thus, GT3 effectively decreased CAs in vivo for up to 30 days after total-body irradiation.

\section{GT3 Increases $R A D 50$ Expression}

Because GT3 decreased the incidence of DSBs in vitro, we reasoned that GT3 may affect expression of the DSB-repair protein RAD50. RAD50 expression in GT3-treated HUVECs was roughly two-fold higher than in vehicle-treated cells (Fig. 4). Irradiation is known to decrease RAD50 expression, and this was, indeed, the case for both GT3- and vehicle-treated cells (Fig. 4); however, GT3 maintained RAD50 expression at a level similar to that observed in non-irradiated, vehicle-treated controls (Fig. 4). These findings suggest that GT3 restricts radiation-induced cytogenetic damage, possibly by modulating RAD50 expression.

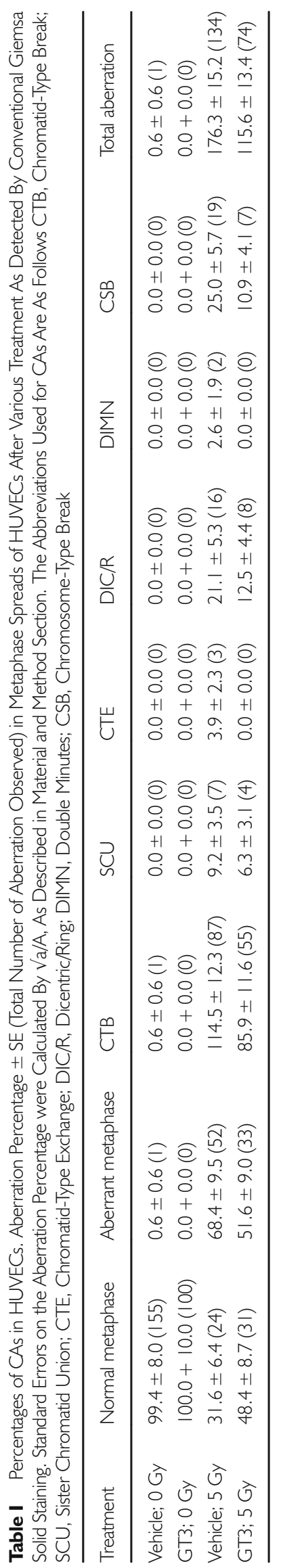


Table II Percentages of CAs in HUVEC Chromosomes I, 2, and 3. Aberration Percentage \pm SE (Total Number of Aberration Observed) in the Metaphase Spreads of HUVECs After Various Treatment As Detected by mFISH Using Whole Chromosome DNA Probe for Human Chromosome I, 2, and 3. Standard Errors on the Aberration Percentage Were Calculated By Va/A, As Described in Material And Method Section

\begin{tabular}{lllllll}
\hline Treatment & Normal metaphase & Aberrant metaphase & Chr-1 & Chr-2 & Chr-3 & Total aberrations \\
\hline Vehicle; 0Gy & $97.1 \pm 7.6(165)$ & $2.9 \pm 1.3(5)$ & $0.6 \pm 0.6(1)$ & $1.2 \pm 0.8(2)$ & $1.8 \pm 1.0(3)$ & $3.5 \pm 1.4(6)$ \\
GT3; 0Gy & $96.5 \pm 7.5(167)$ & $3.5 \pm 1.4(6)$ & $1.2 \pm 0.8(2)$ & $0.6 \pm 0.6(1)$ & $1.7 \pm 1.0(3)$ & $3.5 \pm 1.4(6)$ \\
Vehicle; 5Gy & $38.8 \pm 5.8(45)$ & $61.2 \pm 7.3(7 \mid)$ & $49.1 \pm 6.5(57)$ & $35.3 \pm 5.5(41)$ & $44.0 \pm 6.2(51)$ & $128.4 \pm 10.5(149)$ \\
GT3; 5Gy & $52.7 \pm 8.4(39)$ & $47.3 \pm 8.0(35)$ & $39.2 \pm 7.3(29)$ & $21.6 \pm 5.4(16)$ & $29.7 \pm 6.3(22)$ & $90.5 \pm 11.1(67)$ \\
\hline
\end{tabular}

\section{DISCUSSION}

Radiation generates ROS that often cause DSBs. Studies from various groups, including our own, suggest that GT3 detoxifies ROS, thereby expecting it to reduce DSB formation. Here, we demonstrate that GT3 suppresses DSB formation in irradiated HUVEGs. Specifically, GT3 reduced the number of $\gamma$-H2AX foci, a strong indicator of DSBs, by roughly 29\% in HUVECs. We suggest several mechanisms to explain these findings. GT3 may regulate mitochondrial activity, transcription factors, or endothelial cell surface receptors. For example, GT3 alleviates ROS by preventing mitochondrial dysfunction in primary rabbit renal tubular cells exposed to tert-Butyl hydroperoxide (25). With respect to transcription factors, GT3 decreases ROS in human oral keratinocytes exposed to chemotherapy by stabilizing Nrf2 activation. Nrf2 is a transcription factor that regulates cellular antioxidant pathways (26). Further, we recently demonstrated that GT3 increases the expression and activity of the endothelial surface receptor thrombomodulin (TM) (27). The lectinlike domain of TM activates Nrf2-dependent antioxidant pathways, substantially decreasing serum and renal ROS levels in a mouse model of type-2 diabetic nephropathy (28). Moreover, TM forms a complex with the coagulation factor thrombin to generate activated protein $\mathrm{C}$ (APG) in the blood
(29). Among its many properties, APC prevents glucoseinduced oxidative stress in endothelial cells (30). Thus, our data indicate that GT3 protects HUVEGs from ROSmediated DSBs, and it may do so in a number of ways.

Improperly repaired DSBs induce CAs that are visible in metaphase chromosomes. We found that GT3 decreases CAs in both irradiated HUVECs and primary mouse bone marrow cells. It is not entirely clear how GT3 protects cells from induction of CAs after radiation exposure, but we offer one possible explanation. GT3 induces the production of granulocyte colony stimulating factor (G-CSF) in mice (31) and evidence suggests that G-CSF reduces chromosomal translocations in patients with cancer (32). Specifically, G-CSF prevented translocations between the long arms of chromosomes 8 and 21 in patients with acute myeloid leukemia (32). The role of G-CSF may not be so straightforward, however. G-CSF was shown to cause aneuploidy in healthy individuals (33), although a separate study found no such evidence (34).

Regardless of the specific mechanisms involved, data suggest that various vitamin $\mathrm{E}$ isoforms, including GT3, protect against cytogenetic damage in humans. For example, $\alpha$ tocopherol decreases the frequency of chromatid-type breaks and sister chromatid exchanges in lymphocytes from people with Fanconi anemia $(35,36)$. Similarly, $\alpha$-tocopherol decreases the accumulation of CAs during $\mathrm{G}_{2}$ phase in Down's
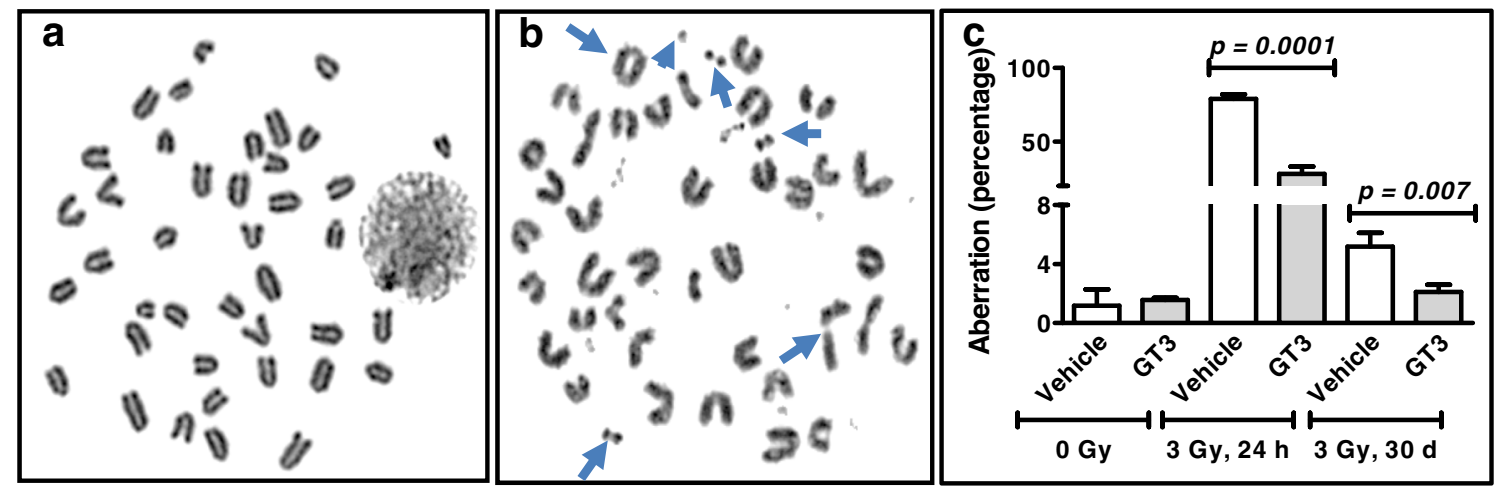

Fig. 2 GT3 decreases radiation-induced CAs in mouse bone marrow cells. CAs were assayed by Giemsa solid staining in mouse bone marrow metaphase spreads from (a) non-irradiated (b) or irradiated mice (CAs indicated by arrows). (c) Mice $(n=3)$ were pretreated with vehicle or GT3 $(200 \mathrm{mg} / \mathrm{kg}) 24 \mathrm{~h} \mathrm{before}$ 3 Gy of total body irradiation. CAs were scored in 200-600 metaphase spreads $24 \mathrm{~h}$ and 30 days after irradiation. Standard deviation represents interindividual $(n=3)$ variability. An unpaired $t$ test was performed to determine $p$ values. 

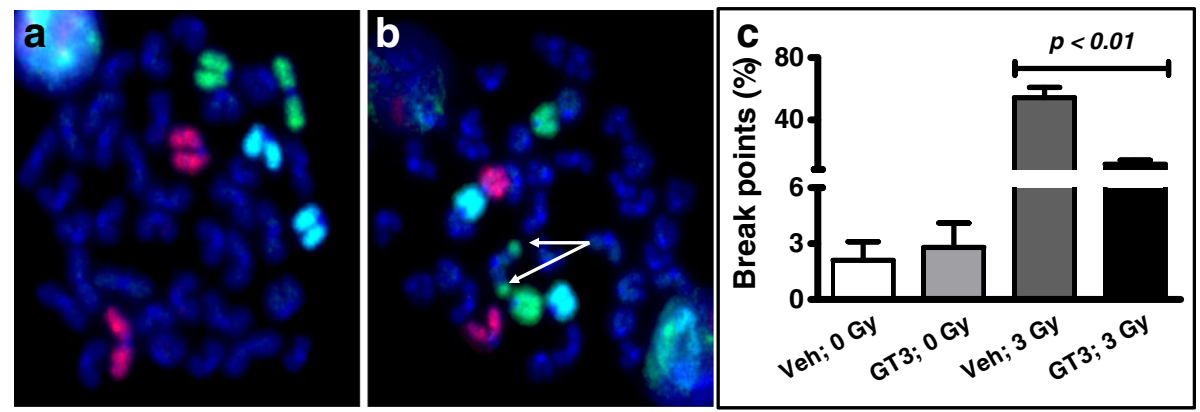

Fig. 3 GT3 decreases radiation-induced CAs in mouse chromosomes I (red), 2 (green), and 3 (blue). CAs were assayed by mFISH in metaphase spreads from (a) nonirradiated or $(\mathbf{b})$ irradiated mice (CAs indicated by arrows). (c) Mice $(n=3)$ were pretreated with vehicle or GT3 (200 mg/kg) $24 \mathrm{~h}$ before 3 Gy of total-body irradiation and pooled bone marrow samples were assayed by mFISH. CAs were scored in 100-300 metaphase spreads and the standard error was calculated by $\sqrt{ }$ a/A as described in materials and method section.

syndrome patients (37). Finally, a commercially available, tocotrienol-rich vitamin $\mathrm{E}$ derivative decreases sister chromatid exchanges in elderly human subjects (38). Thus, multiple vitamin $\mathrm{E}$ isoforms could be used to prevent radiationinduced cytogenetic damage in endothelial cell.

Finally, intracellular DNA-repair enzymes are critically important for repairing cytogenetic damage. Radiation damage activates the cellular DNA-repair machinery that identifies DSBs and recruits DNA-repair proteins. Previously, we found that GT3 modulates as many as 27 gene clusters in HUVECs involved in DNA damage (18). Here, we show that GT3 increases $R A D 50$ expression and attenuates the radiationinduced suppression of RAD50. These findings corroborate a previous study by Li et al. that demonstrated that Rad50 expression was suppressed for up to $48 \mathrm{~h}$ in mouse white blood cells after 8-Gy irradiation (7). Experimental evidence suggests

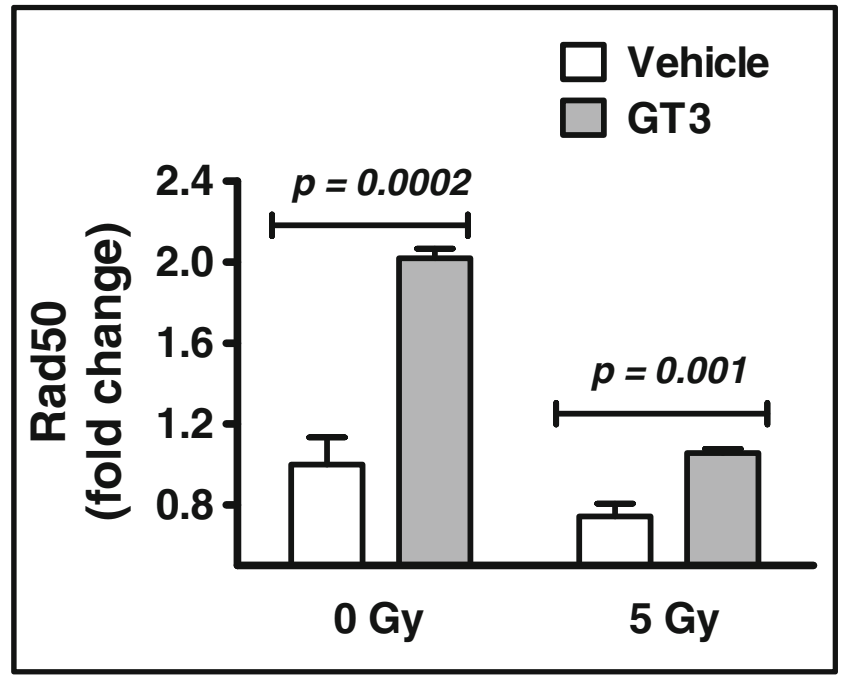

Fig. 4 GT3 modulates RAD50 expression. HUVECs were treated with vehicle or GT3 $(5 \mu \mathrm{M})$ for I h before 0 Gy and 5 Gy irradiation, cells were further incubated for $23 \mathrm{~h}$ before harvest. RAD50 mRNA was measured relative to $18 \mathrm{~S}$ rRNA with Taqman assay. The data are presented as the mean \pm SD of three independent assays. that not only is RAD50 required for efficient DNA repair after irradiation (39) but also that its deficiency makes early embryonic cells hypersensitive to IR (40).

\section{CONCLUSION}

The present studies demonstrate that GT3 pretreatment decreases radiation-induced DSB and CA formation in HUVECs. GT3 also reduces acute and delayed CAs in irradiated mice and increases RAD50 expression in HUVECs. We conclude that GT3 suppresses radiation-induced cytogenetic damage and possibly GT3-mediated alteration in Rad50 expression plays some role in limiting cytogenetic damage after radiation; however, further investigation is required to determine whether GT3 regulates additional DNA-repair proteins. GT3 may, therefore, be a useful therapeutic to protect against radiation-induced genetic diseases.

\section{ACKNOWLEDGMENTS AND DISCLOSURES}

This study was supported by the National Institutes of Health (P20 GM109005 (MH-J), R37 CA71382 (MH-J), and R01 CA148679 [MB]), the US Veterans Administration (MH-J), the Arkansas Space Grant Consortium through the National Aeronautics and Space Administration (NNX15AK32A [RP]), and the National Space Biomedical Research Institute (RE03701) through NCC 9-58 (MB). This publication was made possible, in part, by the Arkansas INBRE program, supported by funding from NIH/NIGMS (P20 GM103429, formerly P20RR016460 [AB]) and the National Center for Research Resources (NGRR P20RR016460, NIGMS - P20 GM103429) from the National Institutes of Health, (AB). These agencies had no role in the study design, data analysis, or the preparation of this manuscript.

This manuscript was edited by Kerry L. Evans from the Office of Grants and Scientific Publications at the University 
of Arkansas for Medical Sciences. Assistance with metaphase chromosome preparation by Joeline Brown and Hemant Kemkar is gratefully acknowledged.

Open Access This article is distributed under the terms of the Creative Commons Attribution 4.0 International License (http://creativecommons.org/licenses/by/4.0/), which permits unrestricted use, distribution, and reproduction in any medium, provided you give appropriate credit to the original author(s) and the source, provide a link to the Creative Commons license, and indicate if changes were made.

\section{REFERENCES}

1. Ward JF. DNA damage produced by ionizing radiation in mammalian cells: identities, mechanisms of formation, and reparability. Prog Nucleic Acid Res Mol Biol. 1988;35:95-125.

2. Pfeiffer P, Goedecke W, Obe G. Mechanisms of DNA doublestrand break repair and their potential to induce chromosomal aberrations. Mutagenesis. 2000;15:289-302.

3. Solomon E, Borrow J, Goddard AD. Chromosome aberrations and cancer. Science. 1991;254:1153-60.

4. MacIntyre DJ, Blackwood DH, Porteous DJ, Pickard BS, Muir WJ. Chromosomal abnormalities and mental illness. Mol Psychiatry. 2003;8:275-87.

5. Trevisan P, Zen TD, Rosa RF, Silva JN, Koshiyama DB, Paskulin GA, et al. Chromosomal abnormalities in patients with congenital heart disease. Arq Bras Cardiol. 2013;101:495-501.

6. Pravit J. Bronchoscopic findings in Down syndrome children with respiratory problems. J Med Assoc Thai. 2014;97 Suppl 6:S15963.

7. Li MJ, Wang WW, Chen SW, Shen Q Min R. Radiation dose effect of DNA repair-related gene expression in mouse white blood cells. Med Sci Monit. 2011;17:BR290-7.

8. Stracker TH, Petrini JH. The MRE11 complex: starting from the ends. Nat Rev Mol Cell Biol. 201 1;12:90-103.

9. Negrini S, Gorgoulis VG, Halazonetis TD. Genomic instability-an evolving hallmark of cancer. Nat Rev Mol Cell Biol. 2010;1 1:220 8.

10. Soloviev AI, Tishkin SM, Parshikov AV, Ivanova IV, Goncharov EV, Gurney AM. Mechanisms of endothelial dysfunction after ionized radiation: selective impairment of the nitric oxide component of endothelium-dependent vasodilation. Br J Pharmacol. 2003;138: 837-44.

11. Akino T, Hida K, Hida Y, Tsuchiya K, Freedman D, Muraki C, et al. Cytogenetic abnormalities of tumor-associated endothelial cells in human malignant tumors. AmJ Pathol. 2009;175:2657-67.

12. Franses JW, Drosu NC, Gibson WJ, Chitalia VC, Edelman ER. Dysfunctional endothelial cells directly stimulate cancer inflammation and metastasis. Int J Cancer. 2013;133:1334-44.

13. Brand M, Sommer M, Ellmann S, Wuest W, May MS, Eller A, et al. Influence of Different Antioxidants on X-Ray Induced DNA Double-Strand Breaks (DSBs) Using gamma-H2AX Immunofluorescence Microscopy in a Preliminary Study. PLoS One. 2015;10, e0127142.

14. Dusinska M, Kazimirova A, Barancokova M, Beno M, Smolkova B, Horska A, et al. Nutritional supplementation with antioxidants decreases chromosomal damage in humans. Mutagenesis. 2003;18: $371-6$.

15. $\mathrm{Xu} \mathrm{Z}$, Hua N, Godber JS. Antioxidant activity of tocopherols, tocotrienols, and gamma-oryzanol components from rice bran against cholesterol oxidation accelerated by $2,2^{\prime}$-azobis $(2-$ methylpropionamidine) dihydrochloride. J Agric Food Chem. 2001;49:2077-81.

16. Ghosh SP, Kulkarni S, Hieber K, Toles R, Romanyukha L, Kao TC, et al. Gamma-tocotrienol, a tocol antioxidant as a potent radioprotector. Int J Radiat Biol. 2009;85:598-606.

17. Berbee M, Fu Q, Boerma M, Pathak R, Zhou D, Kumar KS, et al. Reduction of radiation-induced vascular nitrosative stress by the vitamin $\mathrm{E}$ analog gamma-tocotrienol: evidence of a role for tetrahydrobiopterin. Int J Radiat Oncol Biol Phys. 201 1;79:88491.

18. Berbee M, Fu Q Boerma M, Sree KK, Loose DS, Hauer-Jensen M. Mechanisms underlying the radioprotective properties of gamma-tocotrienol: comparative gene expression profiling in tocoltreated endothelial cells. Genes Nutr. 2012;7:75-81.

19. Kulkarni S, Singh PK, Ghosh SP, Posarac A, Singh VK. Granulocyte colony-stimulating factor antibody abrogates radioprotective efficacy of gamma-tocotrienol, a promising radiation countermeasure. Cytokine. 2013;62:278-85.

20. Parker RA, Pearce BC, Clark RW, Gordon DA, Wright JJ. Tocotrienols regulate cholesterol production in mammalian cells by post-transcriptional suppression of 3-hydroxy-3-methylglutarylcoenzyme A reductase. J Biol Chem. 1993;268:11230-8.

21. Singh VK, Wise SY, Fatanmi OO, Scott J, Romaine PL, Newman VL, et al. Progenitors mobilized by gamma-tocotrienol as an effective radiation countermeasure. PLoS One. 2014;9, el14078.

22. Lee R, Nasonova E, Ritter S. Chromosome aberration yields and apoptosis in human lymphocytes irradiated with Fe-ions of differing LET. Adv Space Res. 2005;35:268-75.

23. Pathak R, Sarma A, Sengupta B, Dey SK, Khuda-Bukhsh AR. Response to high LET radiation 12C (LET, $295 \mathrm{keV} /$ microm) in M5 cells, a radio resistant cell strain derived from Chinese hamster V79 cells. Int J Radiat Biol. 2007;83:53-63.

24. Siveen KS, Ahn KS, Ong TH, Shanmugam MK, Li F, Yap WN, et al. Y-tocotrienol inhibits angiogenesis-dependent growth of human hepatocellular carcinoma through abrogation of AKT/ mTOR pathway in an orthotopic mouse model. Oncotarget. 2014;5:1897-911.

25. Nowak G, Bakajsova D, Hayes C, Hauer-Jensen M, Compadre CM. gamma-Tocotrienol protects against mitochondrial dysfunction and renal cell death. J Pharmacol Exp Ther. 2012;340:330-8.

26. Takano H, Momota Y, Kani K, Aota K, Yamamura Y, Yamanoi $\mathrm{T}$, et al. gamma-Tocotrienol prevents 5-FU-induced reactive oxygen species production in human oral keratinocytes through the stabilization of 5-FU-induced activation of Nrf2. Int J Oncol. 2015;46:1453-60.

27. Pathak R, Shao L, Ghosh SP, Zhou D, Boerma M, Weiler H, et al. Thrombomodulin contributes to gamma tocotrienol-mediated lethality protection and hematopoietic cell recovery in irradiated mice. PLoS One. 2015;10, e0122511.

28. Yang SM, Ka SM, Wu HL, Yeh YG, Kuo CH, Hua KF, et al. Thrombomodulin domain 1 ameliorates diabetic nephropathy in mice via anti-NF-kappaB/NLRP3 inflammasome-mediated inflammation, enhancement of NRF2 antioxidant activity and inhibition of apoptosis. Diabetologia. 2014;57:424-34.

29. Esmon CT. The protein C pathway. Chest. 2003;124:26S-32S.

30. Isermann B, Vinnikov IA, Madhusudhan T, Herzog S, Kashif M, Blautzik J, et al. Activated protein $\mathrm{C}$ protects against diabetic nephropathy by inhibiting endothelial and podocyte apoptosis. Nat Med. 2007;13:1349-58.

31. Kulkarni SS, Cary LH, Gambles K, Hauer-Jensen M, Kumar KS, Ghosh SP. Gamma-tocotrienol, a radiation prophylaxis agent, induces high levels of granulocyte colony-stimulating factor. Int Immunopharmacol. 2012;14:495-503.

32. Ferrara F, Schiavone EM, Palmieri S, Mele G, Pocali B, Scalia G, et al. Complete remission induced by G-CSF in a patient with acute 
myeloid leukemia with $\mathrm{t}(8 ; 21)(\mathrm{q} 22 ; \mathrm{q} 22)$. Hematol J. 2003;4:21821.

33. Nagler A, Korenstein-Ilan A, Amiel A, Avivi L. Granulocyte colony-stimulating factor generates epigenetic and genetic alterations in lymphocytes of normal volunteer donors of stem cells. Exp Hematol. 2004;32:122-30.

34. Hirsch B, Oseth L, Cain M, Trader E, Pulkrabek S, Lindgren B, et al. Effects of granulocyte-colony stimulating factor on chromosome aneuploidy and replication asynchrony in healthy peripheral blood stem cell donors. Blood. 2011;118:2602-8.

35. Pincheira J, Bravo M, Santos MJ, de la Torre C, Lopez-Saez JF. Fanconi anemia lymphocytes: effect of DL-alpha-tocopherol (Vitamin E) on chromatid breaks and on G2 repair efficiency. Mutat Res. 2001;461:265-71.

36. Khabour OF, Soudah OA, Aaysh MH. Genotoxicity assessment in iron deficiency anemia patients using sister chromatid exchanges and chromosomal aberrations assays. Mutat Res. 2013;750:72-6.
37. Pincheira J, Navarrete MH, de la Torre C, Tapia G, Santos MJ. Effect of vitamin E on chromosomal aberrations in lymphocytes from patients with Down's syndrome. Clin Genet. 1999;55:192-7.

38. Chin SF, Hamid NA, Latiff AA, Zakaria Z, Mazlan M, Yusof YA, et al. Reduction of DNA damage in older healthy adults by Tri E Tocotrienol supplementation. Nutrition. 2008;24:1-10.

39. Westmoreland J, Ma W, Yan Y, Van HK, Malkova A, Resnick MA. RAD50 is required for efficient initiation of resection and recombinational repair at random, gammainduced double-strand break ends. PLoS Genet. 2009;5, e1000656.

40. Luo G, Yao MS, Bender GF, Mills M, Bladl AR, Bradley A, et al. Disruption of mRad50 causes embryonic stem cell lethality, abnormal embryonic development, and sensitivity to ionizing radiation. Proc Natl Acad Sci U S A. 1999;96:7376-81. 